Title:

\title{
Vanadyl arsenates as catalysts for selective oxidation of organic sulfides and alkenes
}

Berrocal T, Larrea ES, Iglesias M, Arriortua MI.

Journal of Molecular Catalysis A: Chemical 335(1-2) : 176-182 (2011)

This work is made available online in accordance with publisher policies. To see the final version of this work please visit the publisher's website. Access to the published online version may require a subscription.

\section{Link to publisher's version:}

http://dx.doi.org/10.1016/j.molcata.2010.11.031

Copyright statement: (c) <2011> Elsevier Ltd. Full-text reproduced in accordance with the publisher's self-archiving policy.

This manuscript version is made available under the CC-BY-NC-ND 4.0 license http://creativecommons.org/licenses/by-nc-nd/4.0

\section{cc) (i) $(\Theta)$ \\ BY NC ND}




\title{
VANADYL ARSENATES AS CATALYSTS FOR SELECTIVE OXIDATION OF ORGANIC SULFIDES AND ALKENES
}

Teresa Berrocal ${ }^{a}$, Edurne S. Larrea ${ }^{a}$, Marta Iglesias $^{b}$, Maria I. Arriortua* ${ }^{a}$.

[a]

Dpto. de Mineralogía y Petrología and Dpto. Química Inorgánica

Facultad de Ciencia y Tecnología

Universidad del País Vasco

Apdo. 644 , 48080 Bilbao (Spain)

TLF/FAX: 0034946015984 / 0034946013500

E-mail: maribel.arriortua@ehu.es

teresa.berrocal@ehu.es

[b]

Instituto de Ciencia de Materiales de Madrid, CSIC,

C/ Sor Juana Inés de la Cruz 3,

Cantoblanco, 28049 Madrid (Spain)

\begin{abstract}
Two vanadyl arsenates templated with ethylendiamonium (EnVAs) and piperazonium (PipVAs) were evaluated as catalysts for the oxidation of thioethers and alkenes, using $\mathrm{H}_{2} \mathrm{O}_{2}$ and t-butyl hydroperoxide (TBHP) as oxidants. The intrinsic activity of EnVAs was higher than that of PipVAs for the oxidation of sulfides. Similar results were obtained when using either $\mathrm{H}_{2} \mathrm{O}_{2}$ or TBHP as oxidants. However, the sterical effects were enhanced when TBHP was used and higher selectivities towards sulfoxides were achieved with this oxidant. The catalytic activity of the V-based materials in the epoxidation of simple alkenes and allylic alcohols was assessed. Upon reuse, both materials show no significant decrease in their catalytic properties.
\end{abstract}

Keywords: sulfides oxidation, alkene epoxidation, Vanadyl arsenate. 


\section{1.- INTRODUCTION}

Open-framework metal phosphates are of considerable technological importance as shapeselective catalysts, ion-exchange materials and molecular sieves[1]. Since the discovery of the microporous crystalline aluminophosphates AlPO4-n in 1982[2], a large number of new metal phosphates with open-framework structures have been synthesized[3-7]. These structures contain not only tetrahedrally coordinated atoms but also square pyramidal and octahedral moieties. Among the vast family of open-framework metal phosphates, the transition metal phosphates constitute an important group due to their potential activity as redox catalysts. Out of all the open-framework compounds known, those based on the phosphate oxoanion appear to be the predominant class[8-10]. In addition to the use of tetrahedral phosphate groups as building units, other anionic moieties such as borates[11], arsenates[12], sulphates[13] and selenites[14] have been used successfully in the preparation of novel open framework structures, some of them with catalytic properties. Among these, the arsenates are interesting because, although arsenic belongs to the same group as phosphorous, the larger size of the $\mathrm{AsO}_{4}{ }^{3-}$ anion can give rise to different structures and/or physical properties. Consequently, many arsenate containing frameworks with different structure and composition, have been prepared and characterized[12,15-20].

The incorporation of transition metals, which are able to occur in different oxidation states and/or different coordination numbers within an open-framework structure, would offer the possibility of combining the size and shape selectivity showed by open-framework materials with the catalytic, magnetic, and photochemical properties associated with d-block elements. Some of the transition metals that have been incorporated into microporous frameworks through hydrothermal synthesis in the presence of organic templating agents include $\operatorname{Zn}[3], \mathrm{Co}[4]$, $\mathrm{Fe}[5], \mathrm{Mo}[6]$ and V[7].

Vanadium is of great interest because it is one of the few transition metal cations that can easily adopt different coordination environments. This multicoordinative property of vanadium 
suggests that it is possible to synthesize microporous vanadium arsenates with various structures, as demonstrated by the recent success in hydrothermal assembly of a series of vanadium arsenates with open framework structure[20]. Moreover, vanadium has been tested as a good catalyst in an inorganic vanadyl phosphate[21]. Likewise, a revision of the literature reveals that, although the catalytic studies of inorganic vanadyl phosphates are numerous, there are many few references of templated phosphates with open framework. Furthermore, as far as we are concerned, there is not any vanadyl arsenate templated with an organic molecule with catalytic properties reported, except for the $\left(\mathrm{C}_{5} \mathrm{~N}_{2} \mathrm{H}_{14}\right)\left[(\mathrm{VO})_{3}\left(\mathrm{AsO}_{4}\right)\left(\mathrm{HAsO}_{4}\right)_{2} \mathrm{OH}\right] \cdot 3 \mathrm{H}_{2} \mathrm{O}$ [22], and $\left(\mathrm{C}_{6} \mathrm{~N}_{2} \mathrm{H}_{16}\right)_{0.5}\left[(\mathrm{VO})\left(\mathrm{HAsO}_{4}\right) \mathrm{F}\right][23]$ obtained and studied by our research group.

On the other hand, sulfoxide derivatives are known to have interesting and useful biological and pharmacodynamic properties[24]. The sulfoxides are obtained by oxidation of thioethers by peracids, peroxides and alkyl peroxides using transition metal catalysts[25]. Depending on the catalyst selectivity and the method used, different proportions of sulfoxide and sulfone are produced[26]. In addition, epoxides, produced by the oxidation of olefins, are extremely useful building blocks in the synthesis of organic compounds as they act as excellent intermediates that can yield a great variety of products[27]. When using vanadyl compounds, the catalytically active oxo-peroxo intermediate is formed in situ by oxidation of $\mathrm{V}(\mathrm{IV})$ to $\mathrm{V}(\mathrm{V})$ with an excess of tert-butyl hydroperoxide, yielding a tert-butyl hydroperoxovanadium(V) complex.

In most of the methods described in the literature, pollutants are generated, because of the use of corrosive acids, toxic or dangerous substances[25]. For this reason it is important to develop clean methods which allow obtaining the sulfoxide derivatives and the epoxides without the generation of these undesired substances. In this sense, the use of hydrogen peroxide instead of other oxidants for the oxidation of organic substrates is an interesting alternative because the unique subproduct of the reaction is water. In addition, hydrogen peroxide is highly efficient in its oxygen content and is a cheap reagent. 
The use of open framework phases templated with amines as catalysts in these reactions is especially appealing due to their redox properties, including their acidity[22,23,28,29].

During the course of our research, we have synthesized two new catalytic compounds, fluorovanadyl-hydrogenarsenate with ethylendiamonium and piperazonium as templating agents, with formulae $\left(\mathrm{C}_{2} \mathrm{~N}_{2} \mathrm{H}_{12}\right)_{0.5}\left[(\mathrm{VO})\left(\mathrm{HAsO}_{4}\right) \mathrm{F}\right]$ and $\left(\mathrm{C}_{4} \mathrm{~N}_{2} \mathrm{H}_{14}\right)_{0.5}\left[(\mathrm{VO})\left(\mathrm{HAsO}_{4}\right) \mathrm{F}\right][30]$. In this work the selective oxidation of different thioethers and alkenes, using $\mathrm{H}_{2} \mathrm{O}_{2}$ and t-butyl hydroperoxide (TBHP) as oxidants have been carried out, with the aim of exploring the possibilities of these recently synthesized materials.

\section{2.- Materials and Methods}

\section{1- Materials}

$\left(\mathrm{C}_{2} \mathrm{~N}_{2} \mathrm{H}_{10}\right)_{0.5}\left[(\mathrm{VO})\left(\mathrm{HAsO}_{4}\right) \mathrm{F}\right]$ (EnVAs) and $\left(\mathrm{C}_{4} \mathrm{~N}_{2} \mathrm{H}_{12}\right)_{0.5} \quad\left[(\mathrm{VO})\left(\mathrm{HAsO}_{4}\right) \mathrm{F}\right]$ (PipVAs) were synthesized by mild hydrothermal conditions under autogenous pressure. The compounds were obtained as prismatic light and intense green single-crystals, for EnVAs and PipVAs, respectively. The chemical composition of both compounds was calculated by atomic absorption spectroscopy (AAS) and C, H, N-elemental analysis. The amount of the fluoride anions was calculated by using a selective electrode. The densities, measured by the floatation method[31] in a mixture of bromoform $\left(\mathrm{Br}_{3} \mathrm{CH}, \rho=2.82 \mathrm{~g} \cdot \mathrm{cm}^{-3}\right)$ and chloroform $\left(\mathrm{Cl}_{3} \mathrm{CH}, \rho=\right.$ $\left.1.476 \mathrm{~g} \cdot \mathrm{cm}^{-3}\right)$, are $2.69(2)$ and $2.70(1) \mathrm{g} \cdot \mathrm{cm}^{-3}$, respectively.

The characterization of EnVAs and PipVAs is carefully described in reference 30 and also, it is summed up at the supplementary material of the present article. 


\section{2.- Procedure}

The catalytic experiments were carried out in a batch reactor at atmospheric pressure, at $323 \mathrm{~K}$, and using acetonitrile and dichloromethane as solvent $(3 \mathrm{ml})$. In a typical synthesis, $7.78 \cdot 10^{-3}$ and $7.40 \cdot 10^{-3} \mathrm{mmol}$ of EnVAs and PipVAs, respectively were stirred in a suspension containing the solvent and 0.778 and $0.740 \mathrm{~mol}$ of the corresponding thioethers [methyl phenyl sulfide, methyl p-tolyl sulfide, 4-clorothioanisol and 1-ethylbutyl phenyl sulfide] or olefins [styrene, cyclooctene, linalool and geraniol]. The oxidant, either TBHP (1.1 eq.) or $\mathrm{H}_{2} \mathrm{O}_{2}$ (3 eq., 30\%) was added dropwise, while the overall suspension was heated at $323 \mathrm{~K}$. Samples were taken at regular times, and after filtration, they were analyzed by GCMS using a Hewlett-Packard 5890 II. Since thioethers can be oxidized by $30 \mathrm{wt} \% \mathrm{H}_{2} \mathrm{O}_{2}$ to sulfoxides, blank experiments were carried out under the reaction conditions in order to determine the extension of the uncatalyzed reaction. At $315 \mathrm{~K}$, using acetonitrile as solvent $(10 \mathrm{ml}), 1 \mathrm{mmol}$ of the methyl phenyl sulfide and 3 eq. of $30 \% \mathrm{H}_{2} \mathrm{O}_{2}$, the homogeneous reaction accounted for a conversion of 5 and $15 \%$ after $20 \mathrm{~min}$ and $1 \mathrm{~h}$ of reaction time respectively. Under the same conditions but using 1.1 mmol of TBHP instead of $\mathrm{H}_{2} \mathrm{O}_{2}$, the conversion after $5 \mathrm{~h}$ was $10 \%$. After the end of the catalyzed reactions, the catalysts were filtered and characterized by $\mathrm{X}$ ray diffraction and IR spectroscopy.

\section{3.- Results and discussion}

\section{1.- Synthesis}

The reagents, $\mathrm{V}_{2} \mathrm{O}_{3}$ (2.335 and 2.001 mmol for EnVAs and PipVAs, respectively) and $\mathrm{As}_{2} \mathrm{O}_{5} \cdot 3 \mathrm{H}_{2} \mathrm{O}(3.690 \mathrm{mmol}$ in both cases) were solved in a mixture of $20 \mathrm{ml}$ of water and $10 \mathrm{ml}$ of ethanol for EnVAs and $30 \mathrm{ml}$ of water for PipVAs, then $1 \mathrm{ml}$ of $\mathrm{HF}$ (57.5 mmol) was added in both cases. Finally, the ethylenediamine and piperazine molecules were used to fix the $\mathrm{pH}$ at, approximately, 3 and 1 , respectively. These reaction mixtures were stirred to assure 
homogeneity, sealed in a PTFE-lined stainless steel pressure vessel (filling factor 60\%) and then heated at $170{ }^{\circ} \mathrm{C}$ for 5 days. After reaction, slow cooling, at $30 \mathrm{~K}$ per hour, until room temperature was carried out. The $\mathrm{pH}$ did not show any appreciable change during the hydrothermal treatment. The compounds were obtained as prismatic light and intense green single-crystals, for EnVAs and PipVAs, respectively. The size of the crystals is $0.1 \times 0.08 \times 0.04$ mm for EnVAs and $0.01 \times 0.03 \times 0.01 \mathrm{~mm}$ for PipVAs (Figure SM.1, in the supplementary material). The yield was, approximately, $80 \%$ in both cases.

\section{3.- Structure}

Single-crystal X-ray diffraction data were collected at room temperature on an Oxford Diffraction XCALIBUR2 automatic diffractometer equipped with a CCD detector for EnVAs and on a STOE IPDS (Imaging Plate Difracction System) automatic diffractometer for PipVAs. The structures were solved by direct methods with the SHELXS97 computer program[32]. SHELXL97[33] was used to refine the structure by the least-squares method based on $\mathrm{F}^{2}$. The final atomic coordinates and thermal parameters have been deposited at the Cambridge Crystallographic Data Centre (CCDC 668020 and 668019 for EnVAs and PipVAs, respectively). Crystallographic data, atomic coordinates and selected bond distances and angles are listed in supplementary material, Tables SM.1, SM.2 and SM.3, respectively.

Both phases are layered compounds[30]. The crystal structure consists of a two-dimensional inorganic skeleton, with $\left[(\mathrm{VO})\left(\mathrm{HAsO}_{4}\right) \mathrm{F}\right]^{-}$composition. The sheets are extended along the [100] direction (Figure SM.3). The ethylenediammonium and piperazonium cations are located in the interlayer space (Figure SM.4). These cations stabilize the crystal structure forming, both, ionic interactions and hydrogen bonds with the inorganic framework. Although the connectivity in the inorganic skeleton is the same in both structures, there are differences between them. Due to the bigger size of the piperazonium cation the holes generated into the inorganic layers are wider in 
PipVAs (Figure SM.3). On the other hand this different size generates different reticular space between the inorganic layers, $4.5 \AA$ for EnVAs and $3 \AA$ for PipVAs.

\section{4.- Catalytic properties}

The results given in Figure 1, (a) and (b), and in Table 1 show that for the case of methyl phenyl sulfide, which can penetrate in EnVAs, the activity of EnVAs is higher than the activity of PipVAs, in agreement with the higher intrinsic activity expected for EnVAs. Moreover, the selectivity curves, given in Figure 2, show that the sulfoxide is a primary and unstable product, while the corresponding sulfone appears as a secondary and stable product. Selectivity depends on the oxidant, with $\mathrm{H}_{2} \mathrm{O}_{2}$, EnVAs results also most selective towards the formation of sulfoxide than PipVAs. This would also be consistent with the presence of stronger oxidation sites on EnVAs, taking into account that the oxidation of sulfoxide to sulfone is a more demanding reaction than the oxidation of thioether to sulfoxide. The substrate has a significant influence on the activity and selectivity. The oxidation of the ethylbutyl phenyl sulfide is much slower than that of methyl phenyl sulfide as a consequence of the large size of the reactant. The substituents in the aromatic ring and the more bulky alkyl group imply a decrease in reactivity accompanied by a significant increase in selectivity.

Figures 1 and 2

\section{Table 1}

The oxidant plays an important role in the activity and selectivity. When the reactions were carried out using TBHP as oxidizing agent, analogous results were obtained (Figure 3), i.e. EnVAs is more active than PipVAs for methyl phenyl sulfide and less active for ethylbutyl phenyl sulfide oxidation. The activity follows the order: $\mathrm{H}_{2} \mathrm{O}_{2}>\mathrm{TBHP}>\mathrm{PhC}\left(\mathrm{CH}_{3}\right)_{2} \mathrm{OOH}$ (Figure 3), which is accompanied by an increase in selectivity (Figure 4). 
Figure 3 and 4

The results obtained in the epoxidation of different alkenes (styrene, cyclooctene, linalool and geraniol) using EnVAs and PipVAs based materials as heterogeneous catalysts and $\mathrm{H}_{2} \mathrm{O}_{2}$ and tert-butyl hydroperoxide as the oxygen source, in dichloromethane, are summarised in Table 2. The reaction yields without catalysts run under identical conditions are less than $10 \%$.

Oxidation of styrene, catalyzed by EnVAs and PipVAs using $\mathrm{H}_{2} \mathrm{O}_{2}$ as an oxidant gave styrene oxide, benzaldehyde and 1-phenylethane-1,2-diol as main products, when the reactions were carried out using TBHP as oxidizing agent, analogous results were obtained (Table 2.a). The oxidation of cyclooctene by $\mathrm{H}_{2} \mathrm{O}_{2}$ and TBHP; gave mainly cyclooctene oxide. PipVAs is the most efficient catalyst (Table 2.b).

\section{Table 2}

The title compounds also act as catalyst for the oxidation of linalool (3,7-dimethylocta-1,6-dien3-ol) at temperatures higher than $373 \mathrm{~K}$, to give rise to furans and pyrans, with a greater degree of conversion when increasing the reaction time (Table 2.c). In this case the catalyst acts as a bifunctional system (redox-acid).

The catalysts were also evaluated for the oxidation of geraniol ((E)-3,7-dimethylocta-2,6-dien1-ol). In this case selective oxidation at 6,7-position was achieved with both systems and TBHP as oxidant (Table 2.d).

Reutilisation is one of the greatest advantages of heterogeneous catalysts, and can also provide useful information about the anchoring process and catalyst stability along the catalytic cycle. As can be seen in Table 3, it is clear that neither EnVAs nor PipVAs lose their catalytic efficiency significantly after two catalytic cycles. In addition to these reutilisation tests, leaching tests were carried out. At a conversion value of about $15 \%$, in an oxidation reaction of methyl phenyl sulphide with $\mathrm{H}_{2} \mathrm{O}_{2}$ as oxidizing agent and EnVAs as catalyst, the solid was separated from the reaction media by centrifugation. The supernatant was then allowed to react, and any 
increase of conversion was observed. The residue containing the catalyst was washed twice with acetone and diethyl ether ( $3 \mathrm{~mL})$, and each time, after centrifugation, the organic phase was removed. Finally, fresh reagents were added to the remaining solid and the mixture was allowed to react for, reaching the total conversion after 3 hours of reaction. This is an important result for heterogeneous vanadium-based catalysis and indicates that no deactivation or leaching occurs at least up to three cycles. After the end, the catalyst was filtered and characterized by X ray diffraction and IR spectroscopy. The powder patterns and the infrared spectra did not show any appreciable changes with respect to those obtained before the catalytic reactions (Figures 5 and 6).

Figures 5 and 6

Table 3

The different catalytic behaviour between EnVAs and PipVAs, could be explained taking into account the structural differences between both, as described above. Although the ethylenediammonium is smaller than the piperazonium cation the interlayer space is bigger in the EnVAs catalyst. Furthermore, structural analysis with Topos Program[34] were carried out to evaluate the holes volume between the inorganic skeleton and the organic cations showing bigger volumes in the case of EnVAs. These facts produce a better accessibility of the substrates to the active centres of this catalyst.

\section{4.- Conclusions}

These new vanadium based materials show high catalytic activity in the oxidation of organic sulfides and epoxidation of simple alkenes and allylic alcohols. Material EnVAs proved to be a more efficient catalyst, as can be seen by its greater values of TOF. Both materials were used 
three times with no significant loss of activity, thus indicating that the complexes are stable, which prevents leaching of the active phase and its deactivation.

\section{Acknowledgements}

This work has been financially supported by the "Ministerio de Educación y Ciencia" (MAT2007-60400) and the "Gobierno Vasco" (IT-177-07). The authors thank the technicians of SGIker, Drs. J.C. Raposo, F.J. Sangüesa and A. Larrañaga, financed by the National Program for the Promotion of Human Resources within the National Plan of Scientific Research, Development and Innovation, "Ministerio de Ciencia y Tecnología" and "Fondo Social Europeo" (FSE), for the chemical analyses and the X-ray diffraction measurement respectively.

T. Berrocal wishes to thank the Universidad del País Vasco, UPV/EHU, for funding. 


\section{References}

[1] A.K. Cheetham, G. Férey and T. Loiseau, Angew. Chem., Int. Ed. 38 (1999) 3268 and references therein.

[2] S.T. Wilson, B.M. Lok, C.A. Messina, T.R. Cannan, E.M. Flanigen, J. Am. Chem. Soc. 104 (1982) 1146.

[3] T.E. Gier, G.D. Stucky, Nature 349 (1991) 508.

[4] (a) H. Yuan, J. Chen, G. Zhu, J. Li, J. Yu, G. Yang and R. Xu, Inorg. Chem. 39 (2000) 1476;

(b) P. Feng, X. Bu, S.H. Tolbert and G.D. Stucky, J. Am. Chem. Soc., 119 (1997) 2497 and references therein; (c) P. Feng, X. Bu and G.D. Stucky, Nature 388 (1997) 735; (d) J. Chen, R.H. Jones, S. Natarajan, M.B. Hursthouse, J.M. Thomas, Angew. Chem., Int. Ed. Engl. 33 (1994) 639.

[5] D.R. Corbin, J.F. Whitney, W.C. Fulz, G.D. Stucky, M.M. Eddy, A.K. Cheetham, Inorg. Chem. 25 (1986) 2279.

[6] J. Lu, Y. Xu, N.K. Goh, L.S. Chia, Chem. Commun., (1998) 1709.

[7] G. Bonavia, R.C. Haushalter, J. Zubieta, J. Solid State Chem. 126 (1996) 292.

[8] A.K. Cheetham, G. Férey, T. Loiseau, Angew. Chem. Int. Ed. 38 (1999) 3268.

[9] P.B. Moore, in: J. Niagru, P.B. Moore (Eds.), Crystallochemical Aspects of the Phosphate Minerals, Springer-Verlag, Berlin, 1984.

[10] (a) S. Feng, R. Xu, Acc. Chem. Res. 34 (2001) 239; (b) J. Yu, R. Xu, Acc. Chem. Res. 36 (2003) 481 .

[11] I.D. Williams, M.M Wum, H.H.-Y. Sung, X.X. Zang, J. Yu, Chem.Commun. (1998) 2463.

[12] J. Chem, L. Li, G. Yang, R.R. Xu, J. Chem.Soc., Chem.Commun. (1989) 1217. 
[13] C.N.R. Rao, E.V. Sampathkumaran, R. Nagarajan, G. Paul, J.N. Behera, A. Choudhury, Chem. Mater. 16 (2004) 1441, and references therein.

[14] J.N. Behera, A.A. Ayi, C.N.R. Rao, Chem. Commun. (2004) 968 and references therein.

[15] R.C.Haushalter, Z. Wang, L.M. Meyer, S.S. Dhingra, M.E. Thompson, J. Zubieta, Chem. Mater. 6 (1994) 3845.

[16] S.-L. Wang, Y.-H. Lee, Inorg. Chem. 33 (1994) 3845.

[17] F. Gagnard, C. Resiner, W. Tremel, Inorg. Chem. 36 (1997) 352.

[18] W.T.A. Harrison, M.L.F. Phillips, A.V. Chavez, T.M. Nenoff, J. Mater. Chem. 9 (1999) 3087.

[19] S. Ekambaram, S.C. Sevov, Inorg. Chem. 39 (2000) 2405.

[20] (a) B. Bazán, J.L. Mesa, J.L. Pizarro, L. Lezama, M.I. Arriortua, T. Rojo, Inorg. Chem. 39 (2000) 6056; (b) B. Bazán, J.L. Mesa, J.L. Pizarro, A. Goñi, L. Lezama, M.I. Arriortua, T. Rojo, Inorg. Chem. 40 (2001) 5691; (c) B. Bazán, J.L. Mesa, J.L. Pizarro, M.I. Arriortua, T. Rojo, Mat. Res. Bull. 38 (2003) 3820; (d) B. Bazán, J.L. Mesa, J.L. Pizarro, L. Lezama, J.S. Garitaonandia, M.I. Arriortua, T. Rojo, Solid State Sciences 5 (2003) 1291; (e) B. Bazán, J.L. Mesa, J.L. Pizarro, A. Peña, M.I. Arriortua, T. Rojo, Z. Anorg. Allg. Chem. 631 (2006) 2026; (f) B. Bazán, J.L. Mesa, J.L. Pizarro, L. Lezama, A. Peña, M.I. Arriortua, T. Rojo, J. Solid State Chem. 179 (2006) 1485.

[21] a) P. Amorós, D. Marcos, A. Beltrán-Porter, D. Beltran.Porter, Curr. Opin. Solid State Mat. Sci. 4 (1999) 123; b) H. Imai, Y. Kamiya, T. Okuhara, J. Catal. 255 (2008) 213; c) Y.H. TaufiqYap, A.A. Rownaghi, M.Z. Hussein, M. Irmawati, Catal. Lett. 119(1-2) (2007) 64; d) R. Sen, R. Bera, A. Bhattacharjee, P. Gütlich, S. Ghosh, A.K. Murkerjee, S. Koner, Langmuir 24 (2008) 5970. 
[22] T. Berrocal, J.L. Mesa, J.L. Pizarro, B. Bazán, M. Iglesias, A.T. Aguayo, M.I. Arriortua, T. Rojo, Chem. Comm. (2008) 4738.

[23] T. Berrocal, J.L. Mesa, J.L. Pizarro, B. Bazán, M. Iglesias, J.L. Vilas, T. Rojo, M.I. Arriortua, Dalton Trans. 39 (2009) 834.

[24] A.G. Renwick, in: Sulfur-containing Drugs and Related Organic Compounds, VoL 1, Part B, ed. L.A. Damani, Horwood, Chichester, 1989 p. 133.

[25] F. Bonadies., F. De Angelis, L. Locat., A. Scettri., Tetrahedron Lett. 37(39) (1996) 7129.

[26] D. Alonso, C. Nájera, M. Varea, Tetrahedron Lett. 43 (2003) 3459.

[27] T. Katsuki, Coord. Chem. Rev. 140 (1995) 189.

[28] Villabrille, G. Romanelli, P. Vázquez, C. Cáceres, App. Catal., A 270 (2004) 101.

[29] G. Romanelli, P. Villabrille, C. Cáceres, P. Vázquez, P. Tundo, 13 Congreso Brasilero de Catálise, Foz de Iguacu, Brasil, 2005, 1130.

[30] T. Berrocal, J.L. Mesa, J.L. Pizarro, L. Lezama, B. Bazán, M.I. Arriortua, T. Rojo, J. Solid. State Chem. 181 (2008) 884.

[31] P. Román, J.M. Gutiérrez-Zorrilla, J. Chem. Educ. 62 (1985) 167.

[32] Sheldrick, G. M. SHELXS97. Program for the Solution of Crystal Structures; University of Göttingen: Göttingen, Germany, 1997.

[33] Sheldrick, G. M. SHELXL97. Program for the Solution of Crystal Structures; University of Göttingen: Göttingen, Germany, 1997.

[34] V.A. Blatov, IUCR Compcomm Newsl. 7 (2006) 4. 


\section{Figure Caption}

Figure 1. Kinetic profile for the catalytic oxidation (a) of alkyl aryl sulfides in presence of $\mathrm{H} 2 \mathrm{O} 2$, on EnVAs catalyst; (b) of methyl phenyl sulfide on EnVAs and PipVAs catalysts with $\mathrm{H} 2 \mathrm{O} 2$ and t-BuOOH as oxidants.

Figure 2. Selectivity curves towards sulfoxide in the oxidation of alkyl aryl sulfides in the presence of $\mathrm{H} 2 \mathrm{O} 2$ on EnVAs.

Figure 3. Influence of the oxidant on the oxidation of methyl phenyl sulfide with EnVAS as catalyst.

Figure 4. Influence of the oxidant on the selectivity for sulfoxide with EnVAS as catalyst.

Figure 5. X-ray powder diffraction patterns of EnVAs and of PipVAs before (a and $\mathrm{c}$, respectively) and after the catalytic processes (b and d, respectively).

Figure 6. IR spectra of EnVAs and of PipVAs before (a and c, respectively) and after the catalytic processes ( $b$ and d, respectively).

\section{Table Caption}

Table 1. Conversion $\left(\mathrm{C}_{\mathrm{T}}\right)$, selectivity towards the sulfoxide formation $\left(\mathrm{S}_{\mathrm{SO}}\right)$ and turnover frequency (TOF) data of oxidation reactions of akyl aryl sulfides catalyzed by EnVAs and PipVAs. (All the reactions were carried out between 50 and $60{ }^{\circ} \mathrm{C}$ and with a $1 \%$ of catalysts).

Table 2. Conversion $\left(\mathrm{C}_{\mathrm{T}}\right)$, products percentage and selectivity data for the oxidation of olefins catalyzed by EnVAs and PipVAs. All the reactions were carried out on a $1 \%$ of catalysts and at r.t., except for the epoxidation of linalool, carried out above $373 \mathrm{~K}$.

Table 3. Reutilisation data. Conversion $\left(\mathrm{C}_{\mathrm{T}}\right)$ and selectivity towards the sulfoxide formation $\left(\mathrm{S}_{\mathrm{SO}}\right)$ results at 2 hours of reaction at each cycle. $(\mathrm{T}=323 \mathrm{~K})$. 
Table 1. Conversion $\left(C_{T}\right)$, selectivity towards the sulfoxide formation $\left(S_{S O}\right)$ and turnover frequency (TOF) data of oxidation reactions of akyl aryl sulfides catalyzed by EnVAs and PipVAs. (All the reactions were carried out between 50 and $60{ }^{\circ} \mathrm{C}$ and with a $1 \%$ of catalysts).

\begin{tabular}{|c|c|c|c|c|c|c|c|}
\hline \multirow{2}{*}{ Sulfide } & \multirow{2}{*}{ Oxidant } & \multicolumn{2}{|c|}{$\mathrm{C}_{\mathrm{T}}(\%)($ time, $\mathrm{h})$} & \multicolumn{2}{|c|}{$\mathrm{S}_{\mathrm{SO}}(\%)$} & \multicolumn{2}{|c|}{ TOF $\left(h^{-1}\right)$} \\
\hline & & EnVAS & PipVAS & EnVAS & PipVAS & EnVAS & PipVAS \\
\hline \multirow{3}{*}{ MeSPh } & $\mathrm{H}_{2} \mathrm{O}_{2}$ & $99(2)$ & $96(5)$ & 68 & 28 & 50 & 40 \\
\hline & ТВНP & $100(4)$ & $100(5.5)$ & 84 & 100 & 7 & 37 \\
\hline & $\mathrm{PhC}\left(\mathrm{CH}_{3}\right)_{2}-\mathrm{OOH}$ & $48(24)$ & - & 92 & - & 4 & - \\
\hline \multirow{2}{*}{$\mathrm{MeSPhCH}_{3}$} & $\mathrm{H}_{2} \mathrm{O}_{2}$ & $100(4)$ & $100(4)$ & 81 & 53 & 68 & 38 \\
\hline & TBHP & - & $100(6.5)$ & - & 100 & - & 27 \\
\hline \multirow{2}{*}{ MeSPhCl } & $\mathrm{H}_{2} \mathrm{O}_{2}$ & $100(4)$ & $94(3)$ & 10 & 23 & 52 & 72 \\
\hline & TBHP & - & $100(24)$ & - & 28 & - & 71 \\
\hline EtBuSPh & $\mathrm{H}_{2} \mathrm{O}_{2}$ & $100(7)$ & $100(24)$ & 100 & 100 & 47 & - \\
\hline
\end{tabular}


Table 2. Conversion $\left(C_{T}\right)$, products percentage and selectivity data for the oxidation of olefins catalyzed by EnVAs and PipVAs. All the reactions were carried out on a $1 \%$ of catalysts and at r.t., except for the epoxidation of linalool, carried out above $373 \mathrm{~K}$.

(a) Epoxidation of Styrene

\begin{tabular}{c|cccc|cccc}
\multicolumn{1}{c}{ EnVAs } \\
\cline { 2 - 9 } Oxidant & $\begin{array}{c}C_{T} \\
\text { Epoxi } \\
\text { de } \\
(\%)\end{array}$ & $\begin{array}{c}\text { Other } \\
(\%)\end{array}$ & Sel. $(\%)$ & $\begin{array}{c}C_{T} \\
(\%)\end{array}$ & $\begin{array}{c}\text { Epoxide } \\
(\%)\end{array}$ & $\begin{array}{c}\text { Other } \\
(\%)\end{array}$ & Sel. $(\%)$ \\
\hline$T B H P$ & 16 & 11 & 5 & 69 & 25 & 5 & 20 & 20 \\
$\mathrm{H}_{2} \mathrm{O}_{2}$ & 77 & 3 & 74 & 4 & 83 & 0 & 83 & 0 \\
\hline
\end{tabular}

(b) Epoxidation of Cyclooctene

\begin{tabular}{c|cccc|cccc}
\multicolumn{1}{c|}{} \\
\hline \multirow{3}{*}{ Oxidant } & $\begin{array}{c}C_{T} \\
(\%)\end{array}$ & $\begin{array}{c}\text { Epoxide } \\
(\%)\end{array}$ & $\begin{array}{c}\text { Other } \\
(\%)\end{array}$ & $\begin{array}{c}\text { Selectiviy } \\
(\%)\end{array}$ & $\begin{array}{c}C_{T} \\
(\%)\end{array}$ & $\begin{array}{c}\text { Epoxide } \\
(\%)\end{array}$ & $\begin{array}{c}\text { Other } \\
(\%)\end{array}$ & $\begin{array}{c}\text { Selectiviy } \\
(\%)\end{array}$ \\
\hline$T B H P$ & 4 & 4 & - & 100 & 77 & 77 & - & 100 \\
$H_{2} \mathrm{O}_{2}$ & 10 & 10 & - & 100 & 25 & 25 & - & 100
\end{tabular}

(c) Epoxidation of Linalool

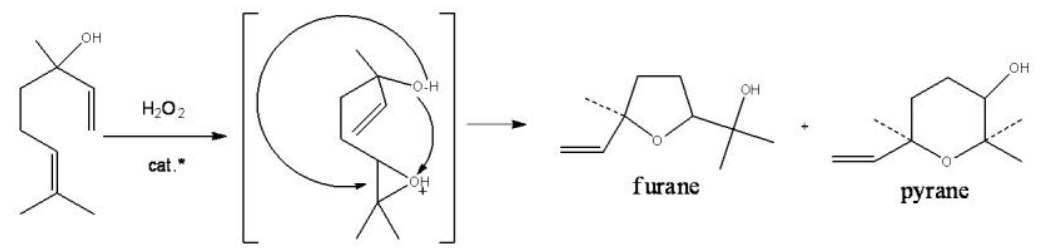

\begin{tabular}{c|cccc|cccc}
\hline \multirow{2}{*}{ Oxidant } & \multicolumn{4}{|c|}{ EnVAs } & \multicolumn{4}{c}{ PipVAs } \\
\cline { 2 - 8 } & $C_{T}(\%)$ & $F(\%)$ & $P(\%)$ & $F / P$ & $C_{T}(\%)$ & $F(\%)$ & $P(\%)$ & $F / P$ \\
\hline$T B H P$ & 100 & 67 & 33 & 2 & 5 & 3 & 2 & 1.5 \\
$\mathrm{H}_{2} \mathrm{O}_{2}$ & 55 & 40 & 15 & 2 & 28 & 18 & 10 & 1.8
\end{tabular}

(d) Epoxidation of Geraniol

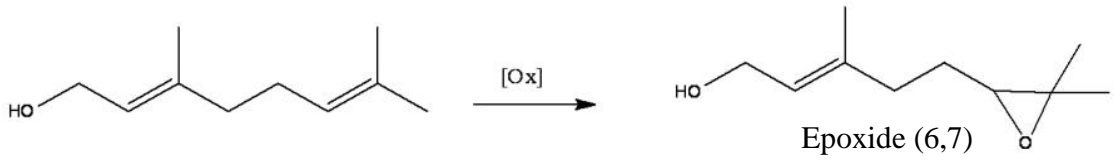

\begin{tabular}{|c|c|c|c|c|c|c|c|c|}
\hline \multirow[b]{2}{*}{ Oxidant } & \multicolumn{4}{|c|}{ EnVAs } & \multicolumn{4}{|c|}{ PipVAs } \\
\hline & $\begin{array}{l}C_{T} \\
(\%)\end{array}$ & $\begin{array}{l}\text { Epoxide } \\
(2,3)(\%)\end{array}$ & $\begin{array}{l}\text { Epoxide } \\
(6,7)(\%)\end{array}$ & $\begin{array}{c}\text { Select. } \\
(6,7)(\%)\end{array}$ & $\begin{array}{c}C_{T} \\
(\%)\end{array}$ & $\begin{array}{l}\text { Epoxide } \\
(2,3)(\%)\end{array}$ & $\begin{array}{l}\text { Epoxide } \\
(6,7)(\%)\end{array}$ & $\begin{array}{c}\text { Selec. } \\
(6,7)(\%)\end{array}$ \\
\hline$T B H P$ & 51 & 7 & 44 & 86 & 33 & 9.5 & 24.5 & 72 \\
\hline $\mathrm{H}_{2} \mathrm{O}_{2}$ & 51 & 25 & 25 & 50 & 47 & 23 & 19 & 40 \\
\hline
\end{tabular}


Table 3. Reutilisation data. Conversion $\left(C_{T}\right)$ and selectivity towards the sulfoxide formation $\left(S_{S O}\right)$ results at 2 hours of reaction at each cycle. $(T=323 \mathrm{~K})$.

\begin{tabular}{cccccc}
\hline \multirow{2}{*}{ Cycle } & \multirow{2}{*}{ Cat/Sust } & \multicolumn{2}{c}{$\mathbf{C}_{\mathbf{T}}(\boldsymbol{\%})$} & \multicolumn{2}{c}{$\mathbf{S}_{\mathbf{S o}}(\boldsymbol{\%})$} \\
& & EnVAs & PipVAs & EnVAs & PipVAs \\
\hline 1 & $1 / 100$ & 99 & 83 & 68 & 41 \\
2 & $1 / 100$ & 100 & 100 & 10 & 36 \\
3 & $1 / 500$ & 98 & 100 & 95 & 92 \\
\hline
\end{tabular}




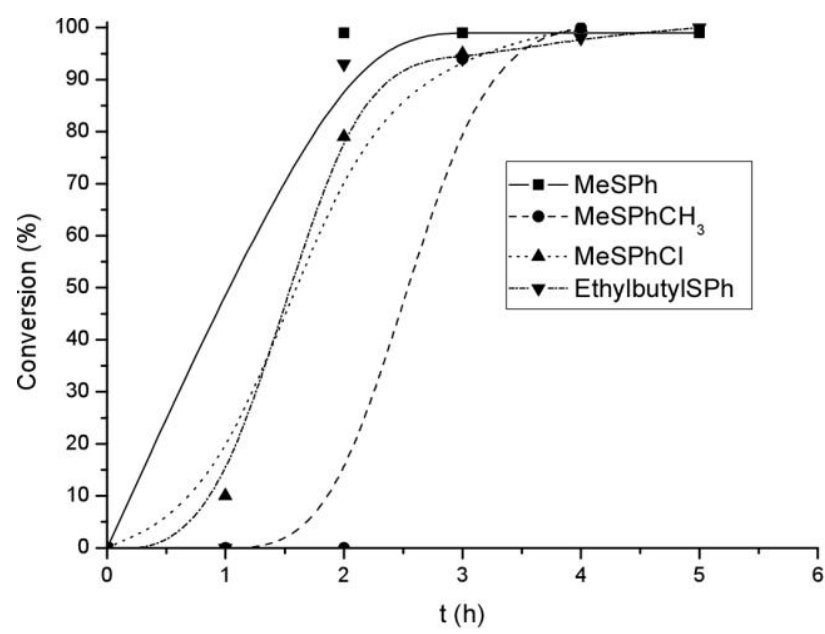

(a)

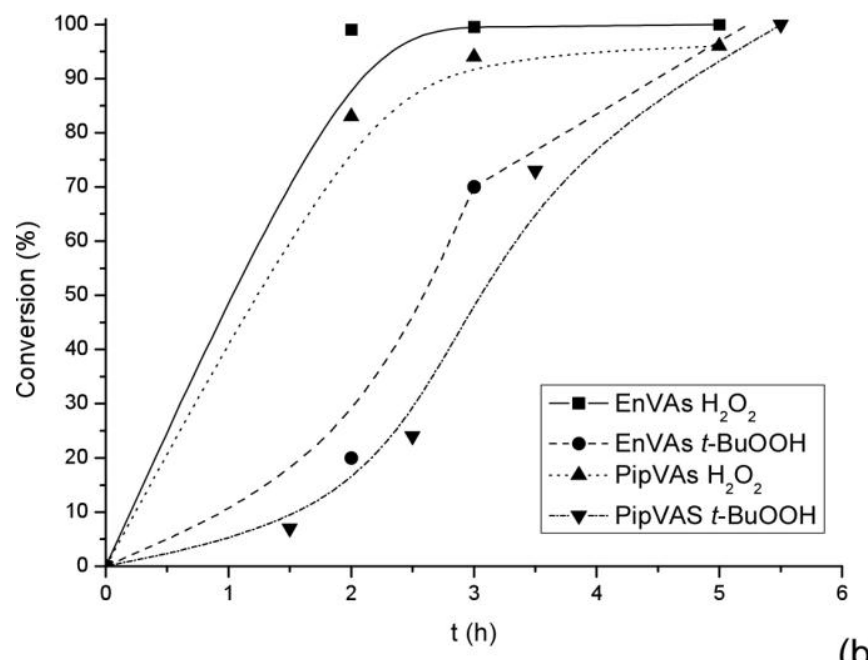

Figure $1 \quad$ Kinetic profile for the catalytic oxidation (a) of alkyl aryl sulfides in presence of $\mathrm{H}_{2} \mathrm{O}_{2}$, on EnVAs catalyst; (b) of methyl phenyl sulfide on EnVAs and PipVAs catalysts with $\mathrm{H}_{2} \mathrm{O}_{2}$ and $t-\mathrm{BuOOH}$ as oxidants. 


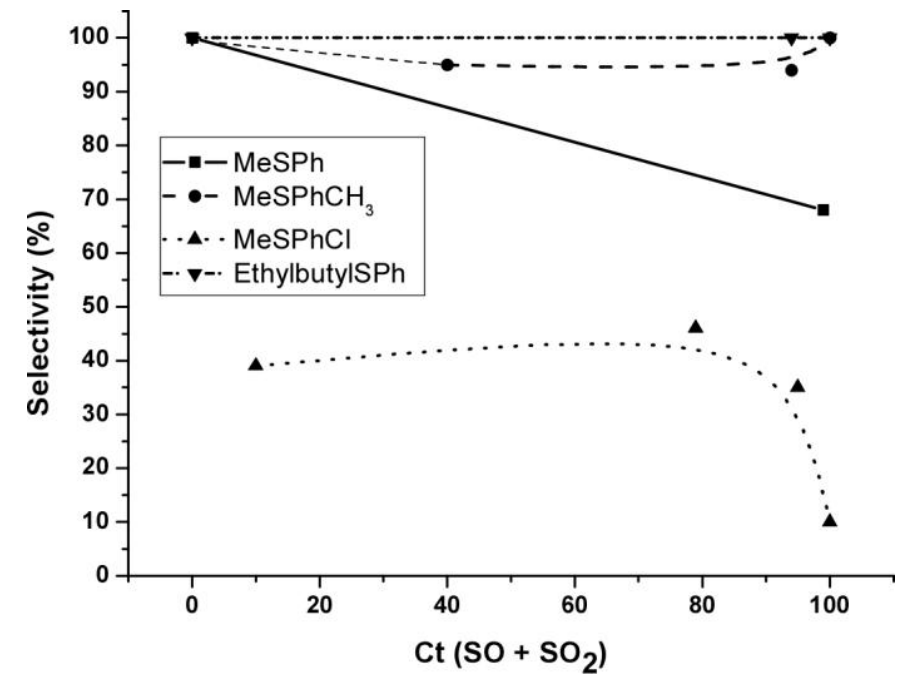

Figure 2. Selectivity curves towards sulfoxide in the oxidation of alkyl aryl sulfides in the presence of $\mathrm{H}_{2} \mathrm{O}_{2}$ on EnVAs.

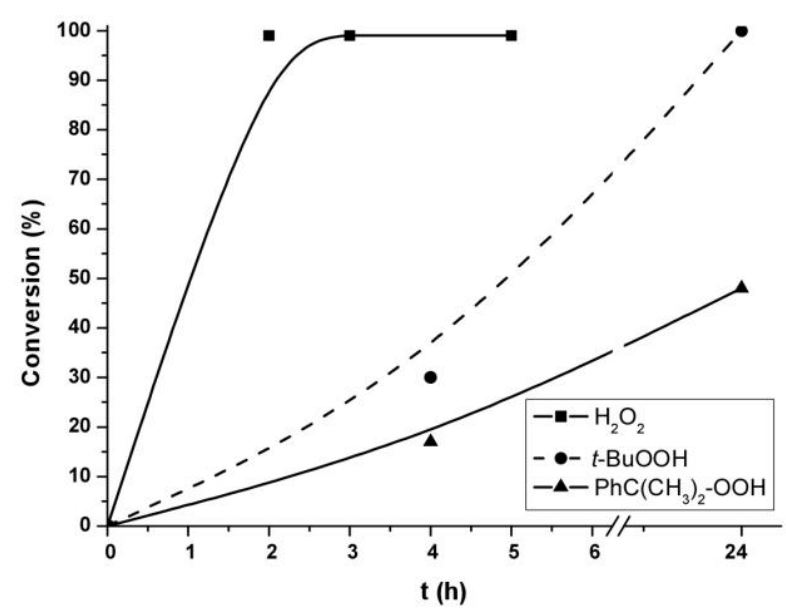

Figure 3. Influence of the oxidant on the oxidation of methyl phenyl sulfide with EnVAS as catalyts. 


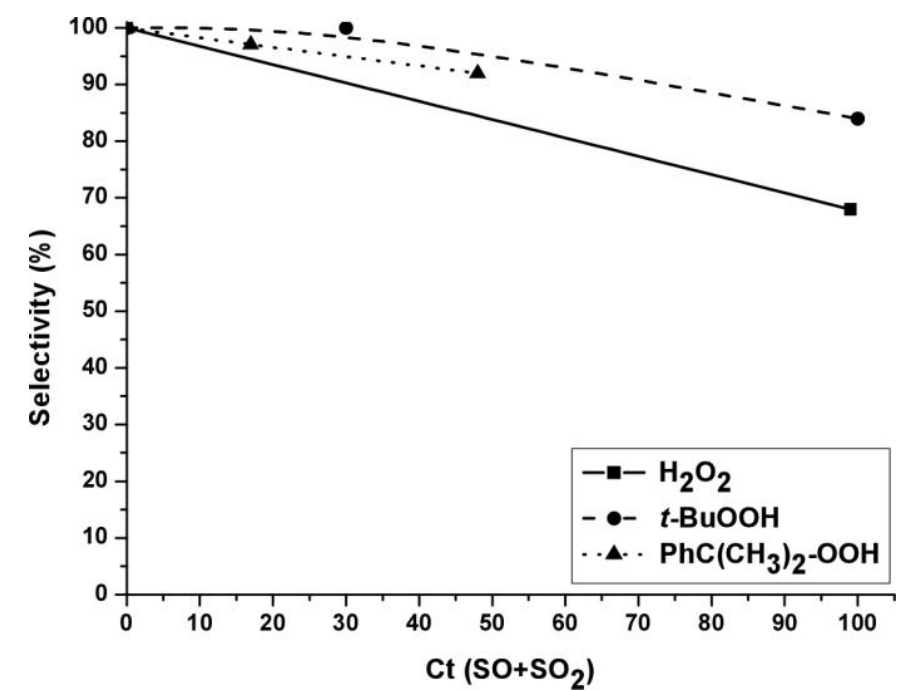

Figure 4. Influence of the oxidant on the selectivity for sulfoxide with EnVAS as catalyst. 

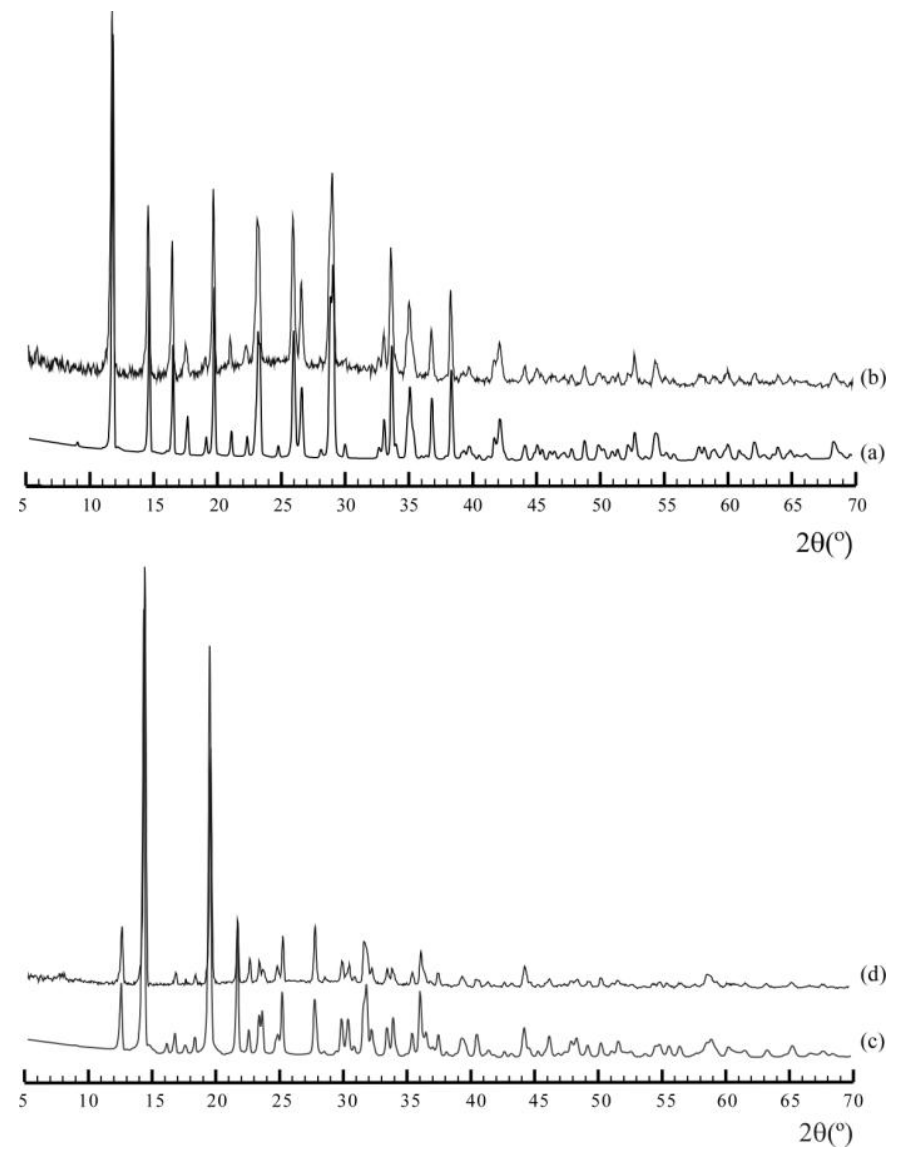

Figure 5. X-ray powder diffraction patterns of EnVAs and of PipVAs before ( $a$ and $c$, respectively) and after the catalytic processes ( $b$ and $d$, respectively). 

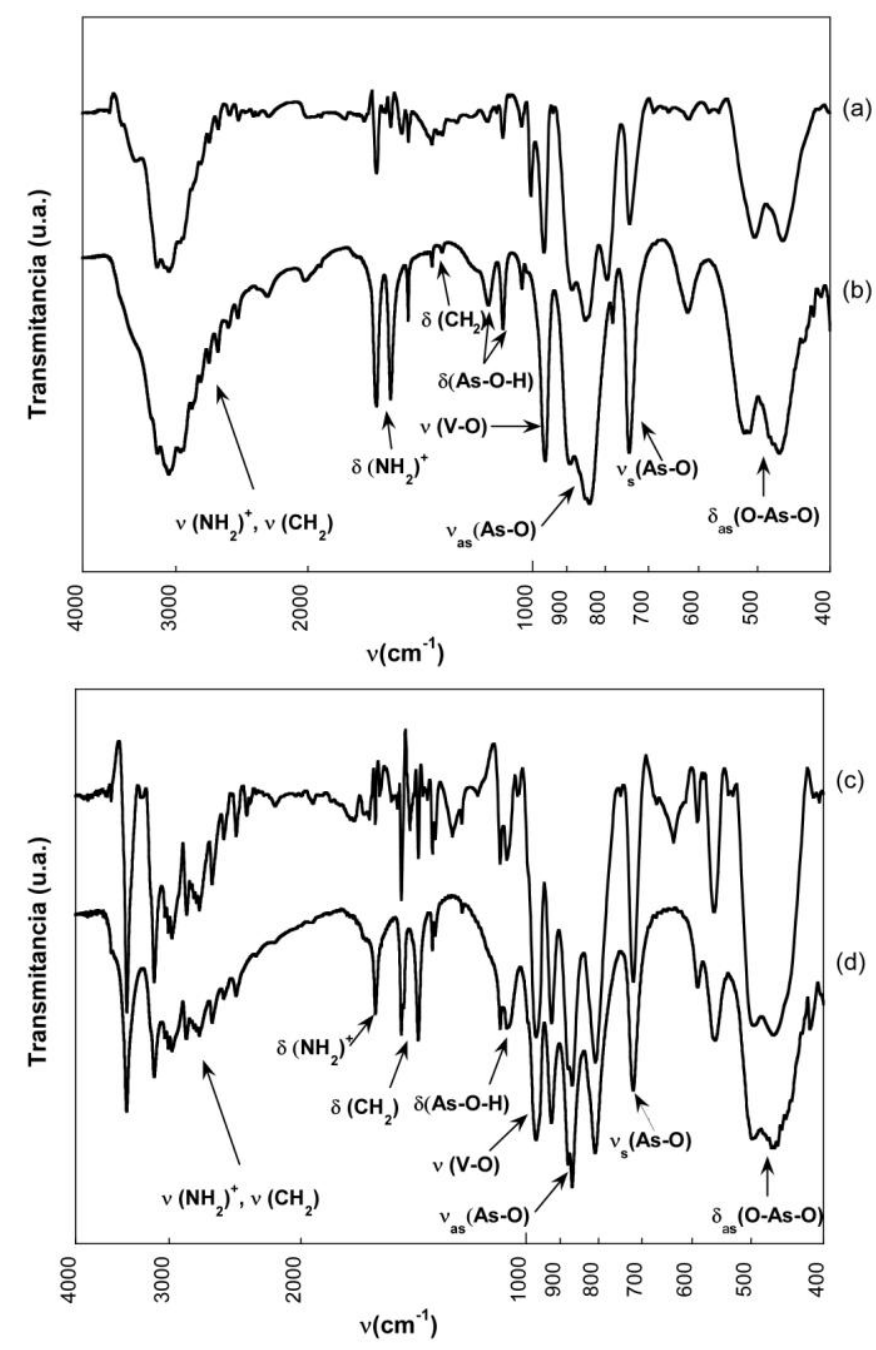

Figure 6. IR spectra of EnVAs and of PipVAs before ( $a$ and $c$, respectively) and after the catalytic processes ( $b$ and $d$, respectively). 


\section{Materials Characterization}

Single-crystals of EnVAs and PipVAs were carefully selected under a polarizing microscope and mounted on a glass fibre (Figure SM.1). Single-crystal X-ray diffraction data were collected at room temperature on an Oxford Diffraction XCALIBUR2 automatic diffractometer equipped with a CCD detector for EnVAs and on a STOE IPDS (Imaging Plate Diffracction System) automatic diffractometer for PipVAs. The Mo-K $\alpha$ radiation was used in both cases. The Lorentz-polarization and absorption corrections were made with the diffractometer software[1,2], taking into account the shape and size of the single-crystals. The structures were solved by direct methods with the SHELXS97 computer program[3]. At the first, the positions of the vanadium (IV), arsenic (V) and the oxygen atoms were located. SHELXL97[4] was used to refine the structure by the least-squares method based on $\mathrm{F}^{2}$. The refinement procedure allowed identifying the rest of the oxygen and fluorine atoms. Scattering factors were taken from Ref. $\left[{ }^{5}\right]$. Anisotropic atomic displacement parameters were used to refine all the atoms, except the hydrogen ones. Details of crystal data, intensity collection and some features of the structural refinement are given in Table SM.1, together with the final Rfactors. The X-ray powder diffraction patterns of both phases were in good agreement with those obtained from the single crystal data. The final atomic coordinates and thermal parameters have been deposited at the Cambridge Crystallographic Data Centre (CCDC 668020 and 668019 for EnVAs and PipVAs, respectively). All structure drawings were made using the ATOMS program[6] (Figures SM.2 and SM.3).

The chemical composition of both compounds was estimated by atomic absorption spectroscopy (AAS), using a graphite camera Zeeman Perkin Elmer 4110 ZL spectrometer, and C, H, N-elemental analysis, with a Euro EA elemental analyzer. The amount of the fluoride anions was measured using a selective electrode. Compound EnVAs has the formula $\left(\mathrm{C}_{2} \mathrm{~N}_{2} \mathrm{H}_{10}\right)_{0.5}\left[(\mathrm{VO})\left(\mathrm{HAsO}_{4}\right) \mathrm{F}\right]$. Calc: N, 5.4; H, 2.3; C, 4.7; As, 29.2; V, 19.8; F, 7.4. Found: N,

5.3; H, 2.2; C, 4.6; As, 29.1; V, 19.7; F, 7.3. The proposed chemical formula for PipVAs is $\left(\mathrm{C}_{4} \mathrm{~N}_{2} \mathrm{H}_{12}\right)_{0.5}\left[(\mathrm{VO})\left(\mathrm{HAsO}_{4}\right) \mathrm{F}\right]$. Calc: $\mathrm{N}, 5.2 ; \mathrm{H}, 2.6 ; \mathrm{C}, 8.9 ;$ As, 27.7; V, 18.9; F, 7.0. Found: N, 
5.1; H, 2.5; C, 8.8; As, 27.5; V, 18.7; F, 6.9. The densities, measured in a mixture of bromoform $\left(\mathrm{Br}_{3} \mathrm{CH}, \rho=2.82 \mathrm{~g} \cdot \mathrm{cm}^{-3}\right)$ and chloroform $\left(\mathrm{Cl}_{3} \mathrm{CH}, \rho=1.476 \mathrm{~g} \cdot \mathrm{cm}^{-3}\right)$, are 2.69(2) and 2.70(1) $\mathrm{g} \cdot \mathrm{cm}^{-3}$, respectively.

Powder X-ray diffraction (XRD) data were collected using a Philips 1470, with BraggBrentano geometry equipped with $\mathrm{Cu}$ anticathode. The measurement conditions were $40 \mathrm{KV}$ and $40 \mathrm{~mA}$, in a angular range of $5<2 \theta<70^{\circ}$, with a step size of $0.02^{\circ}$ in $2 \theta$ and one second for step. An indexation of the diffraction maxima has been carried out by Dicvol program[7] belonging to the WinPlotr software package[8]. In both cases monoclinic cells, a=7.870(2) $\AA$, $\mathrm{b}=7.771(1) \AA, c=10.399(1) \AA$ and $\beta=101.405(1)^{\circ}$ for EnVAs and $a=6.337(2) \AA, b=10.259(1)$ $\AA, c=10.231(1) \AA$ and $\beta=95.055(1)^{\circ}$ for PipVAs, were obtained. The refinements were performed using FullProff program[9], being the results in agreement with those obtained by the single crystal X-ray diffraction (Figure SM.4).

Thermogravimetric analysis (TGA) was conducted on was carried out under synthetic air in a DSC 2960 simultaneous DSC-TGA instrument. Crucibles containing ca. $20 \mathrm{mg}$ of each sample were heated at $5{ }^{\circ} \mathrm{C} \mathrm{min}^{-1}$ in the temperature range $30-800{ }^{\circ} \mathrm{C}$. The thermogravimetric curves show an exothermic mass loss of, approximately, $22 \%$ for both catalysts, in the $250^{\circ} \mathrm{C}$ $340{ }^{\circ} \mathrm{C}$ and $230-340{ }^{\circ} \mathrm{C}$ ranges, for EnVAs and PipVAs, respectively. These mass losses can be attributed to the elimination of the fluoride anion and the organic cation (calc. 19.5 and 23.3\%; exp. 22.0 and $23.0 \%$, respectively). The proposed reaction for this step is: $\left(\mathrm{C}_{2} \mathrm{~N}_{2} \mathrm{H}_{10}\right)$ $\left[(\mathrm{VO})\left(\mathrm{HAsO}_{4}\right) \mathrm{F}\right]_{2}(\mathrm{~s})+(9 / 2) \mathrm{O}_{2} \rightarrow \mathrm{F}_{2}(\mathrm{~g})+2 \mathrm{CO}_{2}(\mathrm{~g})+5 \mathrm{H}_{2} \mathrm{O}(\mathrm{g})+\mathrm{N}_{2}(\mathrm{~g})+2(\mathrm{VO})\left(\mathrm{HAsO}_{4}\right)(\mathrm{s})$. The second mass loss takes place in the $340-575{ }^{\circ} \mathrm{C}$ and $340-480{ }^{\circ} \mathrm{C}$ ranges for EnVAs and PipVAs, respectively. This later step corresponds to the decomposition of the hydrogenarsenate oxoanions and the formation of the inorganic residue, which was not possible identify by X-ray diffraction, because it remained sticky to the crucible (Figure SM.5).

The IR spectrum (KBr pellets) was obtained with a Nicolet FT-IR 740 spectrophotometer in the 400-4000 $\mathrm{cm}^{-1}$ range. The IR spectra (Figure SM.6) of both catalysts exhibit the bands corresponding to the vibrations of the organic dication, vanadyl cations and the $\left(\mathrm{HAsO}_{4}\right)^{2-}$ 
hydrogenarsenate oxoanion. In both phases the $v(\mathrm{~N}-\mathrm{H})$ and $v(\mathrm{C}-\mathrm{H})$ vibrations appear in the $3100-2600 \mathrm{~cm}^{-1}$ ranges; whereas the $\delta(\mathrm{N}-\mathrm{H})$ and $\delta(\mathrm{C}-\mathrm{H})$ vibrations are observed near 1600 and in the $1545-1425 \mathrm{~cm}^{-1}$ ranges, respectively. The anti-symmetrical stretching vibration of the vanadyl cation, $v_{\mathrm{as}}(\mathrm{V}=\mathrm{O})^{2+}$, appears, for both phases, at $1000-930 \mathrm{~cm}^{-1}$, range[10-12]. The antisymmetrical and symmetrical stretching vibration modes of the hydrogenarsenate anions, $v_{\mathrm{as}}\left(\right.$ As-O) and $v_{\mathrm{s}}\left(\right.$ As-O), are observed in the $895-800 \mathrm{~cm}^{-1}$ range and at $720 \mathrm{~cm}^{-1}$, respectively, being located the $\delta_{\text {as }}(\mathrm{O}-\mathrm{As}-\mathrm{O})$ band in the $500-450 \mathrm{~cm}^{-1}$ range. Finally, the bending vibration mode corresponding to the $\mathrm{O}-\mathrm{H}$ bond belonging to the hydrogenarsenate anions is observed in both, the IR and Raman spectra, near $1200 \mathrm{~cm}^{-1}[13]$. 


\section{References}

$\left.{ }^{1}{ }^{1}\right]$ CRYSALIS, version 171.32.5; Oxford Diffraction Ltd.: Oxford, 2007.

[2] STOE X-Area, version 1.39; STOE \& Cie GmbH, 2006.

$\left[{ }^{3}\right]$ Sheldrick, G. M. SHELXS97. Program for the solution of crystal structures; University of Göttingen: Göttingen, Germany, 1997.

$\left.{ }^{4}{ }^{4}\right]$ Sheldrick, G. M. SHELXL97. Program for the solution of crystal structures; University of Göttingen: Göttingen, Germany, 1997.

$\left[{ }^{5}\right]$ International Tables for X-ray Crystallography, vol. IV, Kynoch Press, Birmingham, England, p. 99.

$\left[{ }^{6}\right]$ E. Dowty, ATOMS, A Computer Program for Displaying Atomic Structures, Shape Software, 521 Hidden Valley Road, Kingsport, TN, 1993.

$\left.{ }^{7}\right]$ A. Boulif, D. Coger, Indexing of Powder Difracction Patterns for Low Symmetry Lattices by the Successive Dichotomy Method, J. Apl. Crystallorg., 24 (1991) 987.

$\left[{ }^{8}\right]$ T. Roisnel, J. Rodríguez-Carvajal,WINPLOTR program, 2004.

[9] J. Rodríguez-Carvajal, FULLPROF program. Rietvel Pattern Matching Analysis of Powder Patterns, 2004.

$\left[{ }^{10}\right]$ K. Nakamoto, Infrared and Raman Spectra of Inorganic and Coordination Compounds, John Wiley \& Sons, New York, 1997.

$\left[{ }^{11}\right]$ S. Kamoun, A. Jouini, A. Daoud, J. Solid State Chem. 9 (1992) 18.

$\left[{ }^{12}\right]$ A. Chtioui, L. Benhamada, A. Jouini, Mater. Res. Bull. 40 (2005) 2243.

$\left[{ }^{13}\right]$ S. Kamoun, A. Jouini, A. Daoud, J. Solid State Chem. 99 (1992) 18. 


\section{Figures}

a)

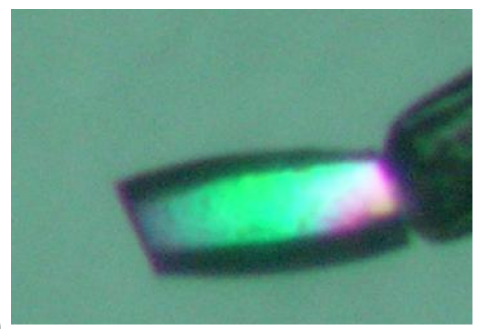

b)

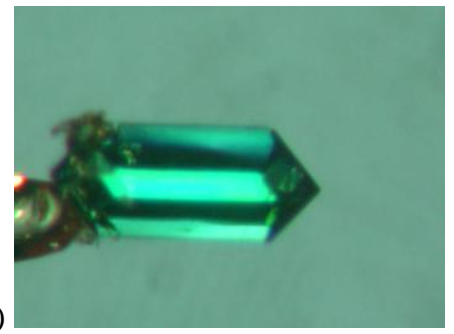

Figure SM.1. Single crystals photographs a) EnVAs $(0.10 \times 0.08 \times 0.04 \mathrm{~mm})$ and b) PipVAs $(0.03 \times 0.01 \times 0.01 \mathrm{~mm})$.

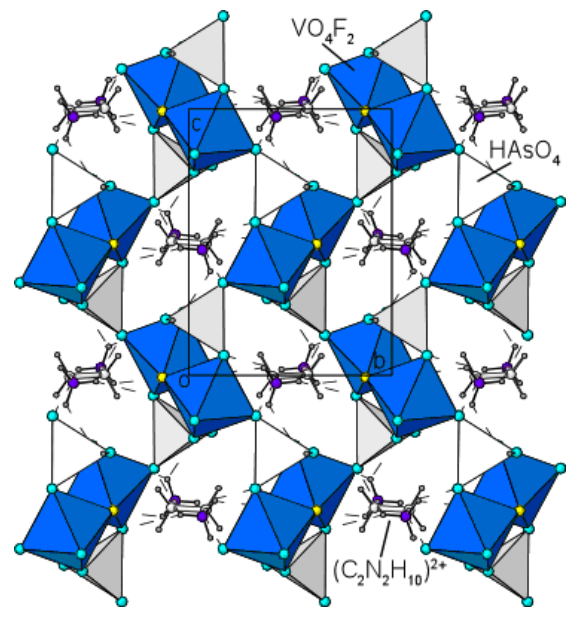

EnVAs

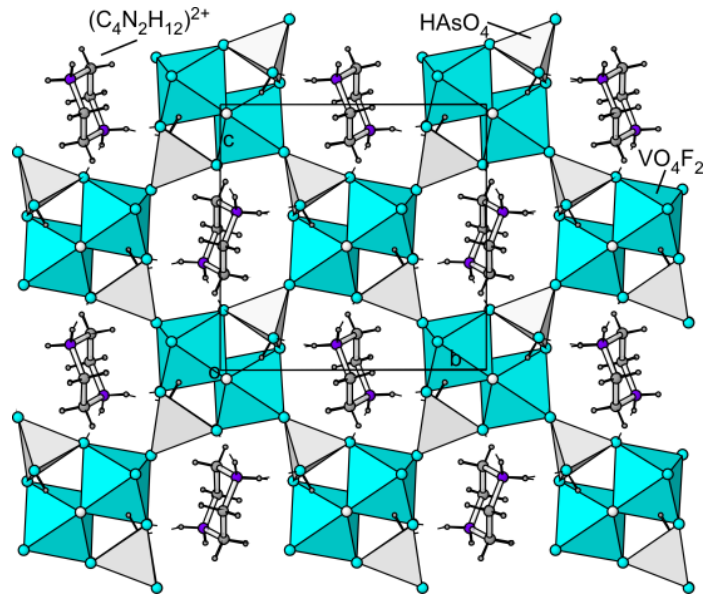

PipVAs

Figure SM.2. Polyhedral representation of the structures of EnVAs and PipVAs in [100] direction. 


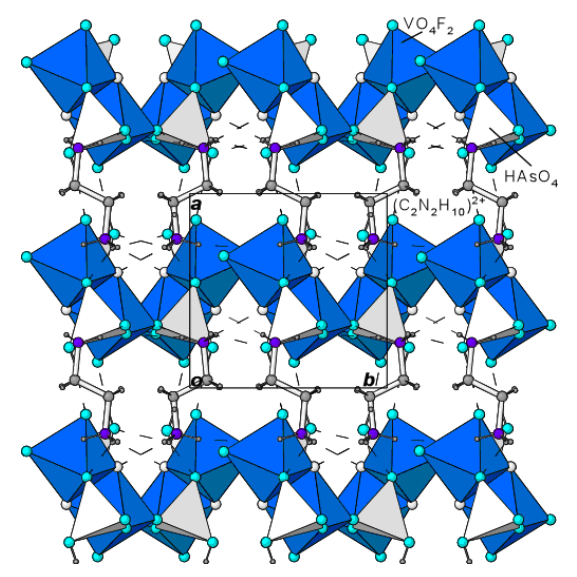

EnVAs

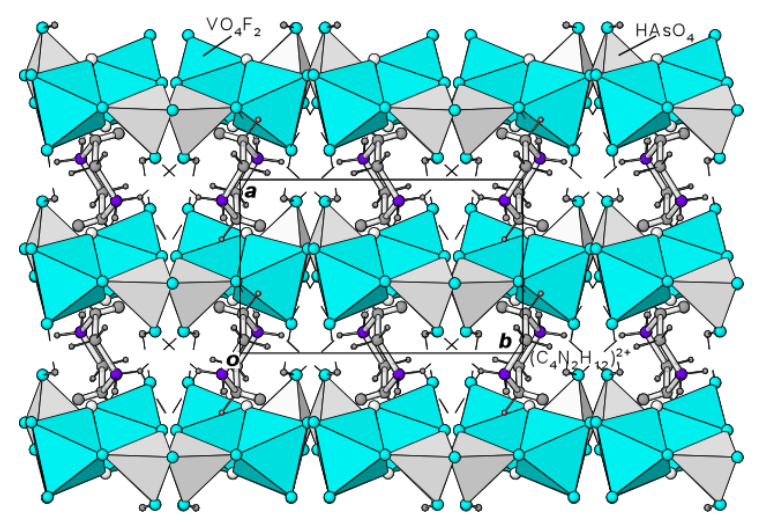

PipVAs

Figure SM.3. Polyhedral representation of the structures of EnVAs and PipVAs in [001] direction.
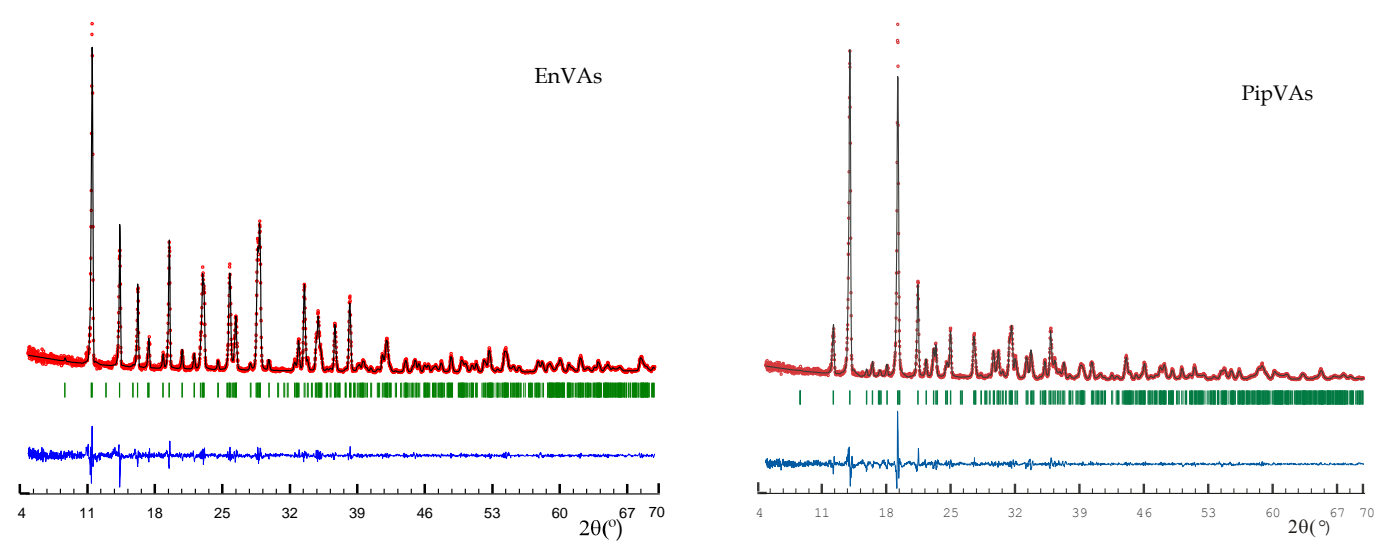

Figure SM.4. Pattern Mattching analices of the powder diffraction data of both catalysts.
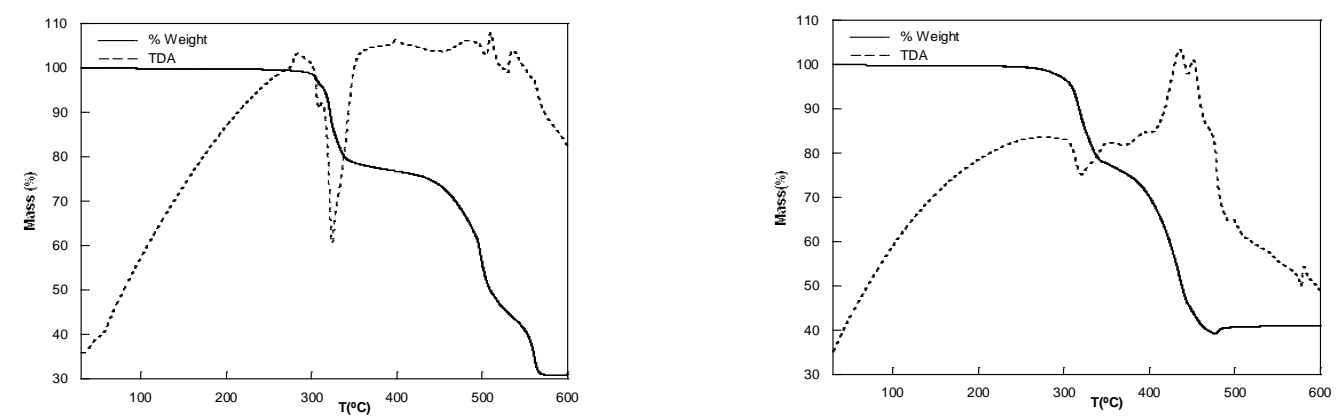

Figure SM.5. Thermogravimetric analyses of EnVAs and PipVAs. 


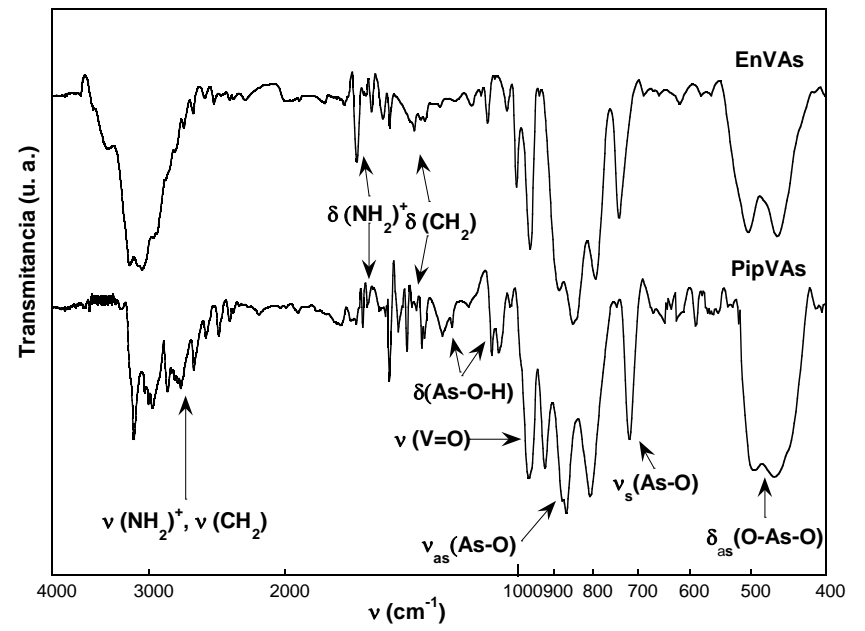

Figure SM.6. Infrarred spectra of EnVAs and PipVAs catalysts. 


\section{Tables}

Table SM.1. Crystal data, details of data collection, and structure refinement for EnVAS and PipVAs.

Empiric Formula

Formula Weight

Crystal System

Space Group ( $\left.\mathrm{N}^{\circ} 33\right)$

$\mathrm{a}, \AA$

b, $\AA$

c, $\AA$

$\beta^{\circ}$

$\mathrm{V}, \AA^{3}$

$\mathrm{Z}$

$\rho_{\text {obs }}, \rho_{\text {calc }}, \mathrm{gr} / \mathrm{cm}^{3}$

$\mathrm{F}(000)$

$\mu \mathrm{mm}^{-1}$

Radiation, $\lambda(\mathrm{Mo} \mathrm{K} \alpha), \AA$

Reflections collected

Independent reflections

$\mathrm{h}, \mathrm{k}, \mathrm{l}$ ranges

$\mathrm{R}$ (int)

$\mathrm{R}[\mathrm{I}>2 \sigma(\mathrm{I})]$

$\mathrm{R}$ [All data]

$\Delta_{\rho \max } \mathrm{y} \Delta_{\rho \min }, \mathrm{e} . \AA^{-3}$

G.O.F

$$
\mathrm{C} \mathrm{N} \mathrm{H}_{6} \mathrm{~V} \mathrm{O} \text { As } \mathrm{O}_{5} \mathrm{~F}
$$

256.93

Monoclinic

$\mathrm{P} 2{ }_{1} / \mathrm{c}$

7.8634(4)

7.7658(4)

$10.4195(6)$

101.524(5)

623.45(6)

4

2.69(2), 2.73

496

6.845

0.71073

2927

1062
$\mathrm{C}_{2} \mathrm{~N} \mathrm{H}_{7} \mathrm{~V} \mathrm{O}$ As $\mathrm{O}_{5} \mathrm{~F}$

269.95

Monoclinic

$\mathrm{P} 2{ }_{1} / \mathrm{c}$

6.301(1)

10.244(1)

10.248(1)

$95.225(1)$

$658.7(1)$

4

$2.70(1), 2.72$

524

6.486

0.71073

4106

1202

$-8 \leq \mathrm{h} \leq 9, \mathrm{k}= \pm 9, \mathrm{l}= \pm 11 \mathrm{~h}= \pm 7, \mathrm{k}= \pm 12, \mathrm{l}= \pm 12$

0.0340

0.0271

$\mathrm{R} 1=0.0301, \mathrm{wR} 2=0.0698 \mathrm{R} 1=0.0197, \mathrm{wR} 2=0.0449$

$\mathrm{R} 1=0.0432, \mathrm{wR} 2=0.0720 \mathrm{R} 1=0.0265, \mathrm{wR} 2=0.0468$

$0.605,-0.488$

$0.356,-0.533$

0.942

0.950

$\left.\mathrm{R} 1=[\Sigma(|\mathrm{Fo}|-|\mathrm{Fc}|)] / \Sigma|\mathrm{Fo}| ; \mathrm{wR} 2=\Sigma\left(\mathrm{w}|\mathrm{Fo}|^{2}-|\mathrm{Fc}|^{2}\right)^{2}\right] / \Sigma\left[\mathrm{w}\left(|\mathrm{Fo}|^{2}\right)^{2}\right]^{1 / 2}$ 
Table SM.2. Fractional atomic coordinates and equivalent isotropic displacement parameters $\left(\AA^{2} \times 10^{3}\right)$ for EnVAs.

\begin{tabular}{ccccc}
\hline ATOMS & $\mathbf{x}$ & $\mathbf{y}$ & $\mathbf{z}$ & $\mathbf{U}(\mathbf{e q})$ \\
\hline $\mathbf{V}$ & $0.3272(1)$ & $0.0885(1)$ & $-0.0965(1)$ & $7(1)$ \\
$\mathbf{A s}$ & $0.3449(1)$ & $0.0609(1)$ & $0.2126(1)$ & $11(1)$ \\
$\mathbf{O}(\mathbf{1})$ & $0.2800(4)$ & $0.1734(4)$ & $0.0754(2)$ & $11(1)$ \\
$\mathbf{O}(\mathbf{2})$ & $0.5433(4)$ & $-0.0247(4)$ & $0.2353(3)$ & $12(1)$ \\
$\mathbf{O ( 3 )}$ & $0.3249(4)$ & $0.1696(4)$ & $0.3487(3)$ & $13(1)$ \\
$\mathbf{O ( 4 )}$ & $0.1346(4)$ & $0.0296(4)$ & $-0.1695(3)$ & $17(1)$ \\
$\mathbf{O}(\mathbf{5})$ & $0.2087(4)$ & $-0.1138(4)$ & $0.2113(4)$ & $19(1)$ \\
$\mathbf{N}(\mathbf{1})$ & $-0.2332(5)$ & $0.0680(5)$ & $0.4708(4)$ & $12(1)$ \\
$\mathbf{C}(\mathbf{1})$ & $-0.0432(6)$ & $0.0856(5)$ & $0.4959(5)$ & $14(1)$ \\
$\mathbf{F}$ & $0.5954(3)$ & $0.1295(3)$ & $0.0075(2)$ & $10(1)$ \\
$\mathbf{H}(\mathbf{1})$ & 0.1090 & -0.0800 & 0.2073 & $68(6)$ \\
$\mathbf{H}(\mathbf{2})$ & -0.2755 & 0.1299 & 0.5292 & $68(6)$ \\
$\mathbf{H}(\mathbf{3})$ & -0.2611 & -0.0423 & 0.4776 & $68(6)$ \\
$\mathbf{H}(\mathbf{4})$ & -0.2780 & 0.1056 & 0.3905 & $68(6)$ \\
$\mathbf{H}(\mathbf{5})$ & -0.0044 & 0.1474 & 0.5773 & $68(6)$ \\
$\mathbf{H}(\mathbf{6})$ & -0.0101 & 0.1521 & 0.4254 & $68(6)$ \\
\hline
\end{tabular}

Table SM.3. Fractional atomic coordinates and equivalent isotropic displacement parameters $\left(\AA^{2} \times 10^{3}\right)$ for PipVAs.

\begin{tabular}{ccccc}
\hline ATOMS & $\mathbf{x}$ & $\mathbf{y}$ & $\mathbf{z}$ & $\mathbf{U}(\mathbf{e q})$ \\
\hline $\mathbf{V}$ & $0.6045(1)$ & $0.1215(1)$ & $-0.0813(1)$ & $6(1)$ \\
$\mathbf{A s}$ & $0.3877(1)$ & $0.1729(1)$ & $0.1861(1)$ & $7(1)$ \\
$\mathbf{O}(\mathbf{1})$ & $0.5557(3)$ & $0.2247(2)$ & $0.0812(2)$ & $11(1)$ \\
$\mathbf{O}(\mathbf{2})$ & $0.4133(3)$ & $0.0131(2)$ & $0.2261(2)$ & $9(1)$ \\
$\mathbf{O ( 3 )}$ & $0.3993(3)$ & $0.2607(2)$ & $0.3213(2)$ & $15(1)$ \\
$\mathbf{O ( 4 )}$ & $0.8304(3)$ & $0.1821(2)$ & $-0.1072(2)$ & $18(1)$ \\
$\mathbf{O ( 5 )}$ & $0.1261(3)$ & $0.1992(2)$ & $0.1212(3)$ & $17(1)$ \\
$\mathbf{N}(\mathbf{1})$ & $-0.1214(4)$ & $0.0620(2)$ & $0.5957(3)$ & $12(1)$ \\
$\mathbf{C}(\mathbf{1})$ & $0.2249(5)$ & $-0.0117(3)$ & $0.5311(3)$ & $14(1)$ \\
$\mathbf{C}(\mathbf{2})$ & $0.0765(6)$ & $-0.0127(3)$ & $0.6370(3)$ & $16(1)$ \\
$\mathbf{F}(\mathbf{1})$ & $0.6918(3)$ & $-0.0249(2)$ & $0.0345(2)$ & $10(1)$ \\
$\mathbf{H}(\mathbf{1})$ & $0.1100(60)$ & $0.1550(30)$ & $0.0470(20)$ & $21(4)$ \\
$\mathbf{H}(\mathbf{2})$ & $0.3380(40)$ & $-0.0660(30)$ & $0.5480(40)$ & $21(4)$ \\
$\mathbf{H}(\mathbf{3})$ & $0.1470(50)$ & $0.0200(30)$ & $0.7100(30)$ & $21(4)$ \\
$\mathbf{H}(\mathbf{4})$ & $0.0410(50)$ & $-0.0940(20)$ & $0.6530(40)$ & $21(4)$ \\
$\mathbf{H}(\mathbf{5})$ & $-0.0990(60)$ & $0.1466(19)$ & $0.5910(40)$ & $21(4)$ \\
$\mathbf{H}(\mathbf{6})$ & $-0.2200(40)$ & $0.0550(30)$ & $0.6520(30)$ & $21(4)$ \\
$\mathbf{H}(\mathbf{7})$ & $0.2660(50)$ & $0.0720(20)$ & $0.5100(30)$ & $21(4)$ \\
\hline
\end{tabular}

